$\sqrt{B}$

J. Bio-Sci. 23: 19-27, 2015

ISSN 1023-8654

http://www.banglajol.info/index.php/JBS/index

\title{
EFFECT OF PHYSIOGRAPHIC FACTORS ON WOODY SPECIES DIVERSITY IN OAK FORESTS (CASE STUDY: SARDASHT FOREST -IRAN)
}

\author{
J Eshaghi-Rad*, A Motallebpour and A Alijanpour \\ Faculty of Natural Resources, Urmia University, Iran
}

\begin{abstract}
Research on species diversity in different gradients of altitudes, aspect and slope is attempting to understand the interactions of vegetation and the non-living environment. The aim of this study was to examine the impact of altitude, slope and aspect variation on the woody species diversity in the Oak forests of Zagros (northern of Iran). 178 samples were taken by using of transect method with a fixed length of $50 \mathrm{~m}$. Altitude, slope, aspect, woody species and diameter at breast height of all trees was recorded in each transect. Margalef richness index, Shannon and Simpson diversity indices and Shannon evenness index were calculated. The Means of the different diversity indices were compared with Kruskal- Wallis test. Results showed that altitude had significant impact on the diversity, richness and evenness of woody species and the middle elevation class $(1400-1600 \mathrm{~m})$ allocated maximum values of indices. Also, the highest species richness was observed in the $(0-20 \%)$ and $(20-40 \%)$ slope classes but the slope hadn't effected on the woody species evenness and diversity. The lowest amount of species richness was observed in the east aspect than other aspects. In general, it can be concluded that the altitude had a large proportion of diversity variation than slope and aspect in the research area.
\end{abstract}

Key words: Iran, Oak, physiographic factors, species diversity, Zagros forest

\section{Introduction}

Zagros forest with area of 5 million hectares is one of the largest biome in Iran. The importance of these forests is not for the production of the industrial woods but also play role in soil and water resources conservation, production of various by-products and preventing air pollution, so it must be managed and maintained properly (Bazyar et al. 2013). Since the degradation and destruction of these forests will follow irrecoverable negative effects, it should be preceded based on a correct and efficient management to the conservation, restoration and achievement to sustainable development by maintaining the natural diversity, because decreasing the natural diversity has led to interference in the natural order and reduce the environmental capacity of these valuable forests. The natural diversity is used as one of the important and fast indicator for determining ecosystem condition because the distribution of species can be investigated by measuring diversity and presented the management recommendations needed with an emphasis on the ecosystem dynamics (Maarel 1988).

The changes of the physiographic factors (altitude, slope and aspect) are parameters affecting the distribution and variety of plants that cause the different species distribution in ecosystems by affecting the characteristics of soil and habitat (Solon et al. 2007). Altitude impacts the climate of region, led to the formation of the climatic areas by affecting the amount and type of precipitation, temperature, evaporation, transpiration and the solar radiations intensity, and therefore the plant types form with the specific natural

\footnotetext{
*Author for correspondence: javad.eshaghi@yahoo.com
} 
diversity (Maguran 2004, Abarghuie et al. 2010). Research conducted in Iran and other parts of the world show that the physiographic factors (especially the altitude factor) will determine the distribution of different plant species. The scale of diversity in the biological form of plants usually decreases with increasing altitude and one or two of the biological form leaves in high altitudes (Paven et al. 2000). The slope is also one of the factors influencing the soil depth and its fertility rate. Soil has greater depth in areas with low slope due to the accumulation of sediments and is more fertile but drainage is more in the steep areas because of less soil erosion. So slope has the important role in the presence or absence of species and their coverage rate (ElGhani 1998, Alhamed 2006). The aspect plays the important role on the distribution and transmittal of species by affecting amount of receiving solar energy, the evaporation rate, precipitation, the soil moisture and fertility.

Many researchers have investigated the diversity of the plant species in relation to physiographic factors (altitude, slope and aspect). Sharma et al. (2009) investigated the altitude effects on the richness, diversity and the dispersal patterns of different tree species in the temperate forests of the Himalayas concluded that all richness indices and diversity had the highest values at low altitudes (1850 to $2250 \mathrm{~m}$ above sea level). Furthermore, Kharakwal et al. (2005) have pointed out that the altitude and climatic variables such as temperature and rainfall determines the richness and diversity of species. Ellu and Obua (2005) have suggested that the different altitudes and slope affect the richness and spatial patterns of the tree species. Mi et al. (2012) illustrated that there was a significant relationship between the aspect and slope and changes in the plant diversity. It was proved by study of Gong et al. (2008) that the aspect was effective on the site productivity and the species composition and diversity in the way that the northern slopes had higher fertility and greater diversity in comparison with the southern slopes. Panthi et al. (2007) stated that Betula utilis and Salix spp distributed in the northern humid aspect with more species richness, but Juniperus indica found in the southern dry conditions with low species richness. It was also observed that species with different ecological amplitudes to the physiographic factors did not give the same niche. Aghaei et al. (2009) studied the effect of altitude factor on plant diversity in temperate forests and concluded that the highest species richness and diversity were found in the low altitudinal range (100 - $400 \mathrm{~m})$. Shirzad and Tabari (2010) illustrated that with increasing slope and altitude, the species diversity reduced. It was observed that physiographic factors directly and indirectly were effective on the distribution and species diversity. Therefore understanding the relationship between vegetation and physiographic factors for estimating type of species for ecological management in different ecosystems is essential (Tamartash et al. 2010).

According to role of physiographic factors in species diversity of woody plants and necessity of investigation of this issue in the Zagros Oak forests which was rich in diversity of Oak species. The aim of this study is to investigate effects of aspect, slope and altitude variation on the diversity of woody species in the northern Zagros forests in Iran.

\section{Materials and Methods}

Study area: The studied area is located in the oak forests of Zagros forests (Iran) and in the south western of Azerbayjan province with area of 25000 hectares and with the coordinates $45^{\circ} 33^{\prime} 25^{\prime \prime}$ longitude and $36^{\circ} 12^{\prime}$ 13 " latitude. Altitudinal range of the study area is $1200-2000 \mathrm{~m}$ above sea level. Parent rock often is the Cretaceous limestone. Average annual rainfall of this region is $724 \mathrm{~mm}$. Average of the maximum temperature is $21^{\circ} \mathrm{C}$ and the average of the minimum temperature is $6^{\circ} \mathrm{C}$. The region has the semi-arid and 
Mediterranean climate (Mohajer 2006). Quercus brantii Lindl and Quercus infectoria Oliv and Quercus libani Oliv and Pyrus communis L. and Pistacia mutica F and M and Crataegus spp. are the tree species in study area.

Method of research: The total number of 178 sample plots were taken using of transect sampling method with fixed length of $50 \mathrm{~m}$ for sampling of tree and shrub cover (Badano et al. 2005). Altitude, percentage of slope and azimuth of aspect were measured in each transect. Then type of species and DBH or diameter at breast height (larger than $5 \mathrm{~cm}$ ) of all trees and shrubs that somehow the crown or trunk intercepting along with the sample line were measured. In order to analyze the data, initially the DBH was transformed to basal area in square meter. Altitude was classified into four categories (1200 - 1400, 1400 - 1600, 1600 - 1800 and $1800-2000 \mathrm{~m}$ ), slope into three level $(0-20 \%, 20-40 \%$ and more than $40 \%)$ and aspects (North, South, East and West). Margalef species richness, Shannon-Wiener evenness, Shannon-Wiener species diversity, and Simpson species diversity were calculated in each transect according to the following formula in Table 1.

Table1. Biodiversity Indices used in this paper.

\begin{tabular}{cc}
\hline Indices & Equation \\
\hline Shannon (H) & $\mathrm{H}=-\sum_{i=1}^{s} p_{i} \ln p_{i}$ \\
Simpson (D) & $\mathrm{D}=1-\sum\left(p_{i}\right)^{2}$ \\
Evenness of Shannon (E) & $\mathrm{E}=\frac{-\sum_{i=1}^{s} p_{i} \ln p_{i}}{\operatorname{Ln} s}$ \\
Margalef (R) & $\mathrm{R}=\frac{S-1}{\operatorname{Ln}(\mathrm{N})}$ \\
\hline
\end{tabular}

S and Pi refer to total number of species in the sample and proportion of each species to total, respectively.

Normality of the data was examined by using Kolmogorov-Smirnov test and since none of the data did not follow of the normal distribution, Kruskal- Wallis test was used for comparison of average different species diversity indices amongst the slope, aspect and altitude categories and to compare pair comparison of indices in different classes of altitude, slope and aspect, Mann-Whitney test was applied. To calculate species diversity indices, PC-ORD ver.5 software and for statistical comparisons, SPSS 18 software were used respectively.

\section{Results}

Results of Kruskal-Wallis test represent the different effects of altitude, slope and aspect on diversity, richness, and evenness. The results showed that the effects of altitude on the diversity, richness and evenness are significant $(p<0 / 05)$. While effect of aspect is significant on the richness and evenness but isn't meaningful on the diversity. The results also showed that the effect of slope is significant on the richness but isn't significant on the evenness and diversity (Table 2). 
Table 2. The result of Kruskal-Wallis test for comparing the mean species diversity indices in altitude, slope and aspect classes.

\begin{tabular}{lcccc}
\hline $\begin{array}{l}\text { Physiographical } \\
\text { factors }\end{array}$ & Diversity indices & Chi-square & df & Sig. \\
\hline & Shannon (H) & 24.24 & 3 & $0.000^{\text {** }}$ \\
& Simpson (D) & 25.96 & 3 & $0.000^{\text {** }}$ \\
Altitude & Evenness (E) & 31.29 & 3 & $0.000^{* *}$ \\
& Margalef (R) & 17.54 & 3 & $0.001^{\text {** }}$ \\
\hline Shannon (H) & 2.62 & 2 & $0.27^{\text {ns }}$ \\
Slope & Simpson (D) & 2.61 & 2 & $0.27^{\text {ns }}$ \\
& Evenness (E) & 3.79 & 2 & $0.15^{\text {ns }}$ \\
& Margalef (R) & 8.14 & 2 & $0.017^{*}$ \\
\hline Shannon (H) & 3.83 & 3 & $0.28^{\text {ns }}$ \\
Simpson (D) & 3.57 & 3 & $0.31^{\text {ns }}$ \\
& Evenness (E) & 16.61 & 3 & $0.001^{* *}$ \\
Margalef (R) & 10.66 & 3 & $0.014^{*}$ \\
\hline
\end{tabular}

${ }^{*},{ }^{* *}$ significant differences at $5 \%$ and $1 \%$ level, respectively.

\section{Effect of altitude on woody species diversity}

The species diversity indices initially increase with increasing altitude and then gradually decrease. The highest values of all calculated indices were observed in the middle altitudinal class $(1400-1600 \mathrm{~m})$ and their lowest ones were observed in the high altitudinal class $(1800-2000 \mathrm{~m})$ (Fig. 1). The pair comparison of the species diversity indices in different altitudinal classes showed that there was statistically significant difference between the Shannon-Wiener, Simpson diversity and Margalef indices in altitudinal classes (1200 - $1400 \mathrm{~m})$ with $(1400-1600 \mathrm{~m})$ and $(1600-1800 \mathrm{~m})$ with $(1800-2000 \mathrm{~m})$. There wasn't significant difference between $(1400-1600 \mathrm{~m})$ and $(1600-1800 \mathrm{~m})$ in none of the indices (Fig. 1). 

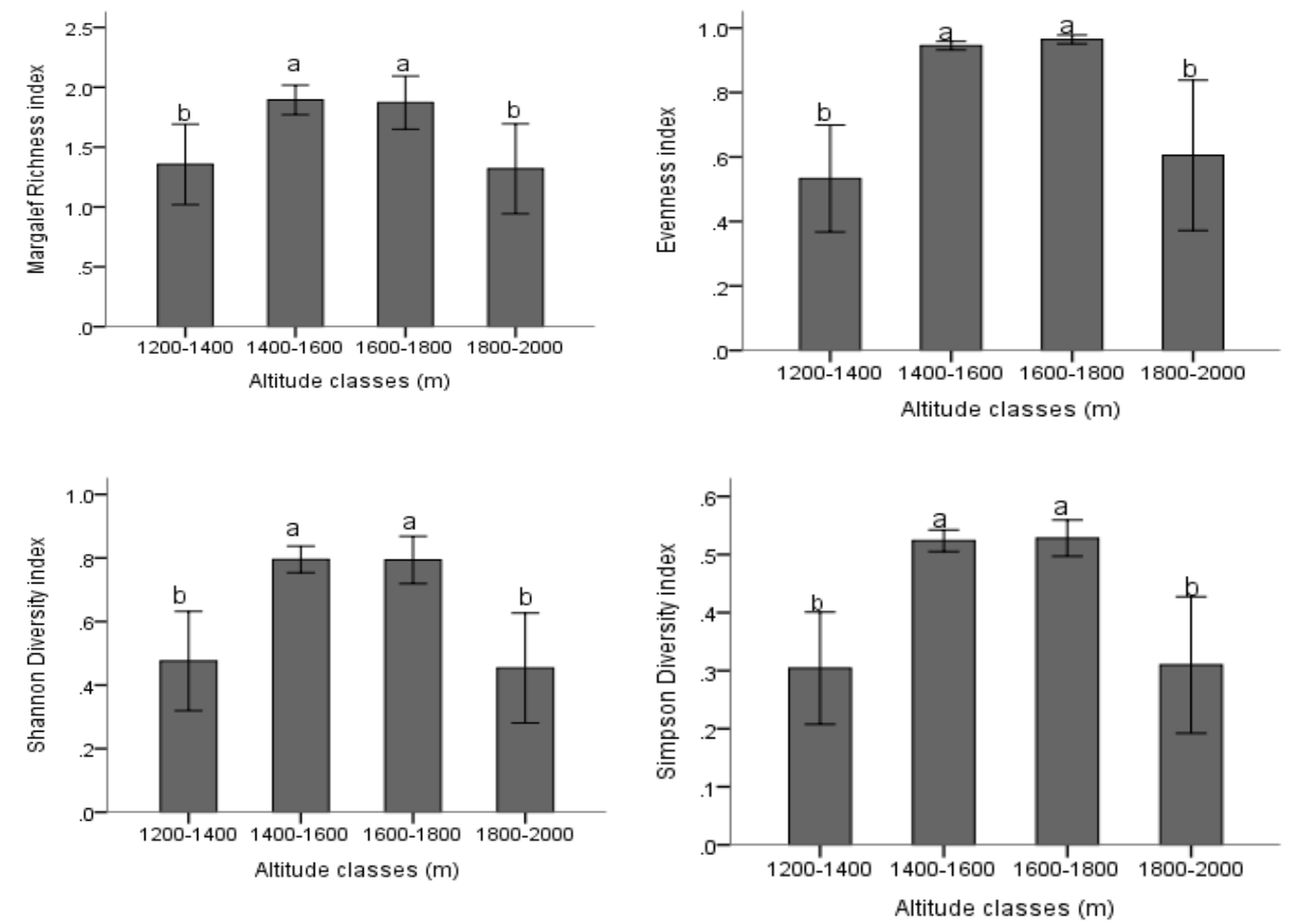

Fig.1. Average indices of richness, Shannon and Simpson species diversity and the Shannon evenness in 4 altitudinal classes (different letters indicate significant difference between the averages).

\section{Effect of slope on woody species diversity}

The highest species richness were observed in the (0 - 20\%) and (20 - 40\%) slope classes. This index was decreased in the upper slope class $(40 \%-60 \%)$. The comparison test of species indices richness means amongst different slope classes illustrated that there were significant differences between the (0 - 20\%) and (20 - 40\%) slope classes and (40\% - 60\%) but the result was similar between the first and second slope classes. The results also showed the Shannon and Simpson species diversity and the Shannon evenness were similar with increasing the slope and there were no significant differences in these indices amongst different slope classes (Fig. 2).

\section{Effect of aspect on woody species diversity}

The lowest amount of species richness was observed in the east aspect. This index was the highest in the north, south and west aspects. The comparison test results showed that there was significant difference between east and other aspects in terms of species richness but this index were the same in the north, south and west aspects. The highest amount of species evenness was observed in the east aspect. The north, south and west had similar values less that east aspect. The comparison test results depicted that there was 
significant difference between east and other aspects. Furthermore the Shannon and Simpson species diversity indices were similar in different aspects and there were no significant differences in these indices amongst different aspects (Fig. 3).
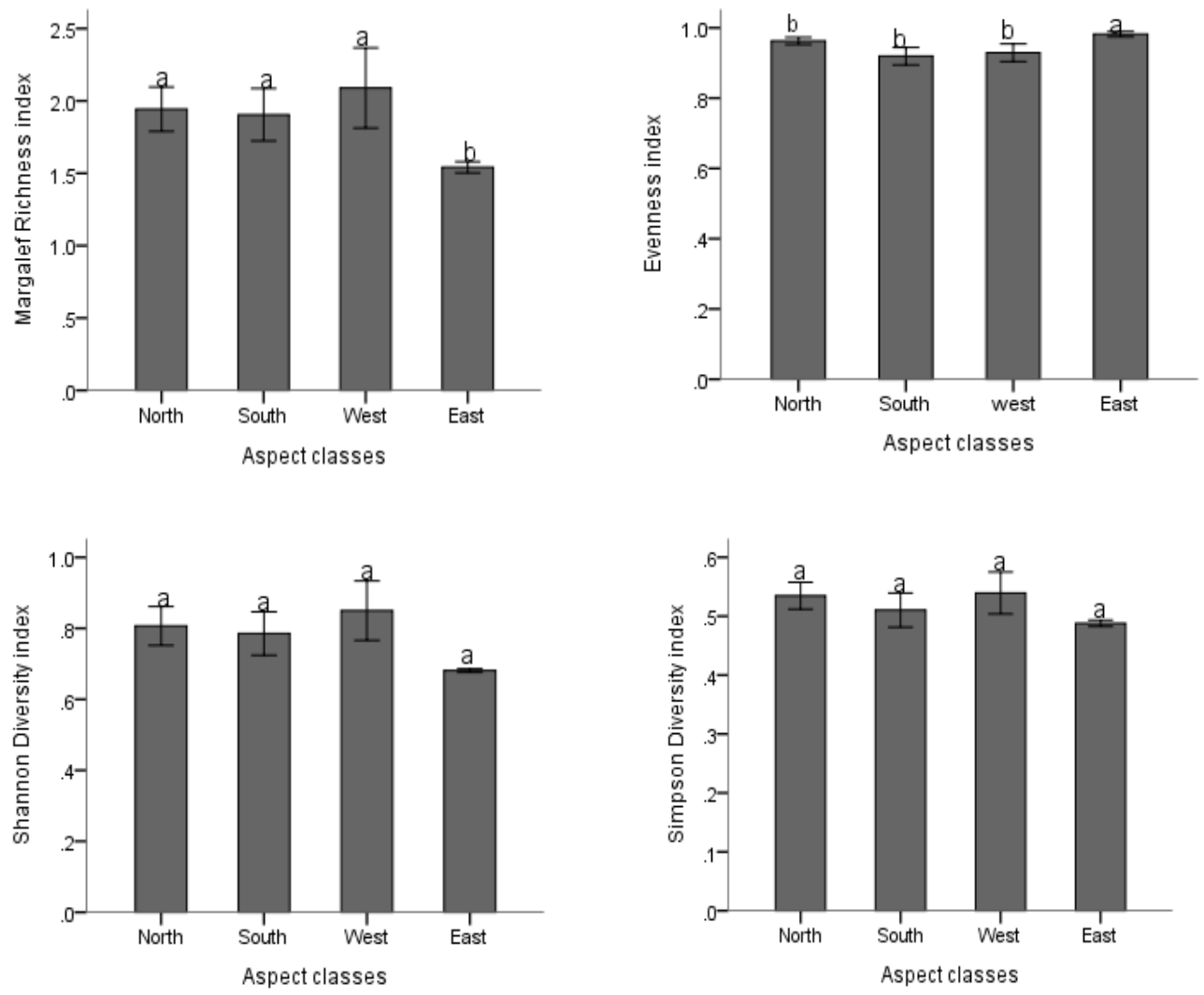

Fig. 3. Average indices of Margalef richness, Shannon and Simpson diversity and Shannon evenness index in four different geographical aspects (different letters indicate significant differences between the averages).

\section{Discussion}

Physiographic factors have caused change in micro-climate and edaphic factors and various ecological niches provide for plants. In fact, research on species diversity in different gradients of altitudes, aspect and slope is attempting to understand the interactions of vegetation and the non-living factors of environment (Hua 2002). Conducted research in the field of vegetation dynamics introduces variation in elevation as one of effective factors in vegetation structure as obvious role on the presence or absence of plant species (Aghaei et al. 2009). The results of present study also showed that the altitudes influences on the diversity, richness and evenness of woody plant species in the region. In this way that the species diversity, richness and evenness increases till middle elevation and then reduces with increasing altitude. This result corresponds with Theory's Grime (1973) based on maximizing diversity in terms of average altitude. Hegazy et al. (1998) also investigated the diversity and abundance of vegetation along the altitudinal gradient dna 
concluded that the middle altitudes were encompassed greater diversity and evenness eras great compared to other classes. Furthermore, Habib et al. (2011) indicated that the tree species diversity and richness increased in the middle part of altitudinal gradient and decreases upward and downward, respectively. They justified this phenomenon because of human activities and deforestation at low altitudes and soil erosion and extreme climatic conditions at high altitudes. The results of Abarghuie et al. (2010) research also illustrated that the altitude had a significant influence on diversity, richness and evenness of plant species and middle altitudinal range had higher diversity, richness and evenness. The present study also is consistent with the abovementioned research results and its reason might be expressed favorable climatic conditions existence and lack of human activity. On the other hand, the aspect by affecting the amount of received solar energy and soil moisture rate always has controlled the type of vegetation (Small et al. 2005, Fontaine et al. 2007). Based on the present research, the aspect had significant effect on the Margalef's richness and evenness of the Shannon-Wiener. Quercus infectoria and Quercus brantii and Quercus libani distributed over eastern aspect while Quercus infectoria, Quercus brantii, Quercus libani, Crataegus spp., Pistacia mutica and Pyrus communis were present in other aspects. With this reason species richness was decreased in the east aspect. The aspects had not a significant effect on species diversity calculated based on species basal area. Shirzad and Tabari (2011) concluded indiscriminate uses and grazing in the past had caused disrupt the balance of diversity in Juniperus excels habitat of Hezar masjed mountains. In this regard, Saberian (2001) also showed that the aspect hadn't a significant relationship with plant diversity and percentage of canopy cover in Semnan province (Iran). But the research of Maranon et al. (1999) conducted in investigating biological diversity of woody shrubs species in the genus Quercus in Strait of Gibraltar and illustrated that the species richness in the southern slope is less than northern slopes. Kabrickt and Shifley (2004) showed that the species diversity was greater in southern aspects in South East Missouri. A study was conducted by Shoshany and Strenberg (2001) on the influence of Mediterranean woody formations in the dry and semi-arid habitats and found that the composition, structure, density and diversity of plant communities alter with the aspect. It can be regarded that the influence of aspect on species diversity were different because of different ecological conditions, types of exploitations, grazing, types of damages, etc. Several studies had represented percentage of slope as one of the effective factors on natural diversity and richness (Maguran 1996, Ellu and Obua 2005, Sohrabi and Akbarinia 2006). The results of the present study showed that slope had significant impact on the Margalef natural richness and there was significant difference between slopes of 20 - 40 class and 40 - 60 class in the study area. Low species richness in the high slopes might be justified by erosion and reducing depth of soil due to slip and drift, reduction in water and humidity holding capacity and loss of soil fertility in areas of steep (El-Ghani 1998, Alhamed 2006). Slope hadn't impact on the diversity and evenness of woody species in the study area. Mirzaei et al. (2008) also achieved similar results. Proctor (1971) and Peet (1981) during their investigation have pointed out that richness and plant species diversity reduction in the steep slope. Takyu et al. (2002) also indicated that the richness and biodiversity rate would increase significantly in the gentle slopes than steep slopes. In general, it can be concluded that among physiographic factors, the altitude had a large proportion of diversity variation than slope and aspect in the area studied. Optimal combination of environmental resources, good thermal conditions and loss human activities had been provided for occurrence of more species in the middle altitudes. Finally, it can be stated that variety study of Zagros forest habitats according to ecological and social special limitations governing on it finds dayto-day more important and recognition of the diversity of plant species information in these habitats and its relation to physiographic factors is issue that requires further investigation and studies. 


\section{References}

Abarghuie EF, Mesdaghi M, Gholami P and Nasrabad NH (2011). The effect of some topographical properties in plant diversity in Stepped Rangelands of Nodushan, Yazd Province, Iran. Iranian Journal of Range and Desert Research 3: $408-419$.

Aghaei SHM, Jalilvand H, Kooch $\mathrm{Y}$ and Poormajidian MR (2011). Plant diversity with respect to ecological factor of altitude in Sardabrood forests of Chalous, N. Iran, Iranian Journal of Biology 24: 400-411.

Alhamad MN (2006). Ecological and species diversity of arid Mediterranean grazing land vegetation, Journal of Arid Environments 66: 698-715.

Badano El, Cavierse LA, Molina-Montenegro MA and Quiroz CL (2005). Slope aspect influences plant association patterns in the Mediterranean Motorral of central Chile, Journal of Arid Environment 62: 93-108.

Bazyar M, Haidari M, Shabanian N and Haidari H (2013). Impact of physiographic factors on the plant species diversity in the North Zagros forest (case study, Kurdistan province, Marivan region), Annals of Biological Research 4: 317-324.

Ellu G and Obua J (2005). Tree condition and natural regeneration in disturbed sites of Bwindi Impentrable forest national park, Tropical Ecology 49: 99-111.

Ghani EMM (1998). Environmental correlates of species distribution in arid desert ecosystems of eastern Egypt Governal, Arid Environments 38: 297-313.

Fontaine M, Aerts R, Ozkan K, Mert A, Gulsoy S, Suel H, Waaelkens M and Muys B (2007). Elevation and exposition rather than soil type determine communities and site suitability in Mediterranean mountains forests of southern Anatolia, Turkey, Forest Ecology and Management 247: 18-25.

Gong X, Brueck H, Giese KM, Zhang L, Sattelmacher B and Lin S (2008). Slope aspect has effect on productivity and species composition of hilly grass land in the Xilin River Basin, Inner Mongolia, China, Journal of Arid Environment 72: 483-493.

Grime JP (1973). Competitive exclusion in herbaceous vegetation, Nature 242: 344-347.

Habib T, Malik ZH and Khan MQ (2011). Plant species diversity along the altutidinal gradient at Garhi Dopatta Hills, Muzafarabad, Journal of Medicinal Plants Research 5: 5194-5196.

Hegazy AK, Demedesh MA and Hosni HA (1998). Vegetation, species diversity and floristic relations along an altitudinal gradient in South-West Saudi Arabia, Journal of Arid Environment 3: 3-13.

Hua Y (2002). Distribution of plant species richness along elevation gradient in Hubei Province, China, International Institute for Earth System Science. Nanjing, China 1-140 pp.

Kabrickt MJ and Shifley RS (2004). Oak forest composition, site quality and dynamics in relation to site factors in the southeastern Missouri Ozarks, USDA Forest Service, 1-311 pp.

Kharakwal G, Mehrotra p and PangteyYS (2005). Phytodiversity and growth form in relation to altitudinal gradient in the Central Himalayan (Kumaun) region of India, Current Science 89: 873-878.

Maguran AE (1996). Ecological diversity and its measurement. Chapman and Hall, 1-256 pp.

Maguran AE (2004). Measuring biological diversity. Blackwell Publishing, UK, 1-256 pp.

Maranon T, Ajbilou R, Ojeda F and Arroya J (1999). Biodiversity of woody species in oak woodland of southern Spain and northern Morocco, Forest Ecology and Management 115:147-156.

Maarel VE (1998). Species diversity in plant communities in relation to structure and dynamics, SPB Academic publishing, Hague, The Netherlands, 1-114.

Mohajer MR (2007). Silviculture. University of Tehran press, Tehran, 1-387. 
Mi Z, Hua KZ, Zhu JY and Bin G (2012). Analysis on slope revegetation diversity in different habitats, Earth and Planetary Science 5: 180-187.

Mirzaei J, Akbarinia M, Hosseini SM, Sohrabi H and Hosseinzade J (2008). Biodiversity of herbaceous species in relation to physiographic factors in forest ecosystems in Central Zagros, Journal of Iranian Biology 20: 375-382.

Panthi MP, Chaudhey RP and Vetaas OR (2007). Plant species richness and composition in a trans- Himalayan inner valley of Manang district, Central Nepal, Himalayan Journal of Science 4: 57-64.

Paven NP, Hernandez Trejo H and Rico Gray V (2000). Distribution of plant life forms along an altitudinal gradient in the semi-arid valley of Zapotitnal, Mexico, Journal of Vegetation Science 11: 39-42.

Peet RK (1981). Forest vegetation of the Corolado Front Range, Vegetation 45: 3-75.

Perma R and Joybari S (2010). Effect of physiographic and human on canopy cover and woody species diversity in Zagros forest (case study: protected forests, Ghalajeh, Kermanshah), Iranian Journal of Forest and Poplar Research18: 539-555.

Proctor J (1971). The plant ecology of surpertine II. Plant response to serpentine soils, Journal of Ecology 50: 397-410.

Sharma CM, Suyal S, Gairola S and Ghildiyal SK (2009). Species richness and diversity along an altitudinal gradient in moist temperate forest of Garhwal Himalaya, Journal of American Science 5: 119-128.

Shirzad MA and Tabari M (2011). Effect of some environmental factors on diversity of woody plants in Juniperus excelsa habitat of Hezarmasjed mountains, Iranian Journal of Biology 6: 800-808.

Small CJ and McCarthy BC (2005). Relationship of understory diversity to soil nitrogen, topographic variation, and stand age in an eastern Oak forest, USA, Forest Ecology and Management 217: 229-243.

Sohrabi H and Akbarinia M (2006). Study on plant species diversity in relation to physiographic factors in Dehsorkh, Javanroud, Iranian Journal of Forest and Poplar Research 13: 294-279.

Solon J, Degorski M and Roo Zielinska M (2007). Vegetation response to a topographical-soil gradient, Catena Journal 71: 309-32.

Strenberg M and Shoshany M (2001). Influence of slope aspect on Mediterranean woody formations, Comparison of a semi-arid and arid site in Israel, Ecological Research 16: 335-345.

Takyu M, Aibas SI and Kanehiro K (2002). Effects of Topography on tropical lower montage forests under different geological conditions on Mount Kinabalu, Borneo, Plant Ecology 159: 35-49.

Tamartash R, Yousefian M, Tatian MR and Ehsani M (2010). Vegetation Analysis in Rangeland of Lasem, Iran, Agriculture and Environment Science 7: 397-401. 
